\title{
Electrochemical Investigation of Interaction of Candida albicans with Titanium-Nickel Implant in Human Saliva
}

\author{
Bin Qiao ${ }^{1}$, Tao $\mathrm{Lv}^{2 *}$ \\ ${ }^{1}$ College of Plant Protection, Northwest A\&F University, Taicheng Road, Yangling District, Xianyang \\ City, Shanxi Province 712100, P.R. China \\ ${ }^{2}$ Guangzhou Medical University, GuangZhou, Guangdong 510182, P.R. China \\ *E-mail: taoluopursuit@ sina.com
}

Received: 24 October 2021 / Accepted: 3 December 2021 / Published: 5 January 2022

\begin{abstract}
Titanium and its alloys have been widely adopted in dental prosthetics due to their excellent biocompatibility, light weight, high resilience and good corrosion resistance. The human oral cavity is the second largest microbial host system after the human intestine, with a large number of microbial species. This complex environment of multiple groups of microorganisms promotes the formation of biofilms on the surface of oral implant titanium materials, leading to possible peri-implant inflammation which accelerates the surface corrosion of the titanium implant material. Candida albicans is a common fungus, and the study of the interaction between Candida albicans and titanium alloys is of great importance for the later systematic study of the corrosion effect of the fungus on the metal. In this study, fluorescence microscopy, scanning electron microscopy and electrochemical analysis techniques were adopted to systematically study the formation of microbial films of Candida albicans on the surface of titanium-nickel alloy. The electrochemical behavior of the corrosion of titanium-nickel alloy by Candida albicans were investigated with open circuit potential, potentiodynamic polarization curves and electrochemical impedance spectroscopy. The combined action of metabolites produced by Candida albicans, the extracellular polymer matrix and the formation of microbial film led to the changes in the corrosion electrochemistry of titanium-nickel alloy.
\end{abstract}

Keywords: Candiada albicans; Titanium alloy; Biofilm; Corrosion; Potentiodynamic polarization

\section{$\underline{\text { FULL TEXT }}$}

(C) 2022 The Authors. Published by ESG (www.electrochemsci.org). This article is an open access article distributed under the terms and conditions of the Creative Commons Attribution license (http://creativecommons.org/licenses/by/4.0/). 